\title{
É POSSÍVEL FALAR EM SIGNO E SEMIOSE DOCUMENTÁRIA?
}

\author{
IT IS POSSIBLE TO SPEAK IN DOCUMENTARY SIGN AND SEMIOSIS?
}

\author{
Marilda Lopes Ginez de Lara \\ Doutora em Ciências da Comunicação pela ECA-USP \\ Professora do Departamento de Biblioteconomia e Documentação da ECA-USP \\ Pesquisadora do $\mathrm{CNPq}$ - Modalidade Produtividade em Pesquisa \\ larama@usp.br
}

Comente este artigo no blog Ebibli $=\underline{\text { http: } / / \text { encontros-bibli-blog.blogspot.com } /}$

\begin{abstract}
Resumo
São discutidas as contribuições da abordagem lingüístico-semiótica para a compreensão do funcionamento da linguagem documentária, bem como a possibilidade do signo e da semiose documentária. Apresenta-se uma síntese dos principais conceitos da semiótica - signo, objeto, interpretante, experiência colateral e semiose - e procura-se caracterizar o signo documentário e a semiose documentárias focando particularmente dois sistemas semióticos relacionados: a linguagem natural e a linguagem artificial. Conclui-se pela caracterização do signo documentário como um signo particular, cujo funcionamento depende do caráter construído da linguagem documentária e da remessa a interpretantes nos discursos e terminologias das áreas focalizadas.
\end{abstract}

Palavras-chave: Semiótica. Linguagem documentária. Signo documentário. Semiose documentária. Interpretação documentária.

\section{INTRODUÇÃO}

Dentre as metodologias de construção de linguagem documentária - LD, destacamos as que utilizam, como referência, o modelo da língua e a observação de seu funcionamento, cujas bases principais são as contribuições teóricas da lingüística saussuriana (CINTRA et al., 2002). As versões contemporâneas dessa teoria compreendem, entre outras, desenvolvimentos elaborados a partir da abordagem semiótica (LOPES, 1984; DASCAL, 1978), cujo aporte é considerado fundamental para dar conta do processo de interpretação. $\mathrm{Na}$ perspectiva de Saussure, considera-se que o ponto de partida é o fato social subjacente a todo ato de fala, ou seja, a língua. Já na perspectiva de Peirce, o conceito fundamental é o de semiose, ou o processo onde alguma coisa funciona como signo, ou seja, significa, e que compreende o signo, ou representamen, o interpretante e o objeto, ao qual se acrescentou depois o intérprete e o contexto, segundo proposta de Morris (DASCAL, 1978). A combinação das duas perspectivas permite considerar os aspectos pragmáticos que Saussure havia 'deixado de fora': a realização do ato sígnico, ao qual concorrem elementos relacionados ao contexto, às 
circunstâncias de enunciação e ao usuário.

A perspectiva de Saussure é centrada na língua enquanto sistema. A língua, parte da linguagem e produto social da faculdade de linguagem, é ao mesmo tempo um conjunto de convenções adotadas pelo corpo social para que essa faculdade possa ser exercida pelos indivíduos. Diferentemente da linguagem, a língua é um todo por si mesmo, um princípio de classificação (SAUSSURE, 1969).

Língua e fala são estreitamente ligadas e se implicam mutuamente. A língua existe na coletividade, é aprendida naturalmente deste o nascimento dos indivíduos e se apresenta como a "soma dos sinais depositados em cada cérebro, mais ou menos como um dicionário cujos exemplares, todos idênticos, fossem repartidos entre os indivíduos" (SASSURE, 1969, p.27). É um padrão coletivo. A fala, ao contrário, é constituída pelas combinações individuais que dependem da vontade daqueles que falam. "Nada existe (...) de coletivo na fala: suas manifestações são individuais e momentâneas" (idem, p. 28).

Para Saussure, os estudos da língua e da fala constituem "dois caminhos impossíveis de trilhar ao mesmo tempo" (idem ibidem). O nome de Lingüística poderia ser conservado para cada uma dessas duas disciplinas, podendo-se falar numa Lingüística da fala, mas seria necessário não confundi-la com a Lingüística propriamente dita, "aquela cujo objeto é a língua" (idem ibidem). É o ponto de vista da língua, então, o escolhido pelo teórico de Genebra. Essa separação, porém, é a causa de inúmeros questionamentos que, muitas vezes, sem negar a teoria, põem em relevo seus limites.

$\mathrm{Na}$ realidade, as abordagens do signo lingüístico que se seguem à postulada por Saussure são inúmeras. Dentre elas, a perspectiva semiótica, em vez de se centrar exclusivamente no estudo da língua enquanto sistema estrutural, volta-se aos aspectos relacionados ao seu uso nas diversas circunstâncias e situações. Muitas dessas abordagens não abandonam a proposta saussuriana, mas a enriquecem ao focar o intrincado jogo existente entre a produção do signo lingüístico, sua comunicação e interpretação.

Há uma espécie de nó comum entre os estudos semiológicos de Saussure e a Semiótica de Peirce. Enunciadas quase à mesma época, as idéias de Peirce se voltam à observação dos fenômenos onde certos objetos funcionam como "signos". A Semiótica procura formular uma definição geral de signo, identificar os elementos presentes quando qualquer coisa funciona como signo, analisar as relações entre tais elementos e propor uma classificação dos signos, como uma tipologia dos sistemas de signos (DASCAL, 1978).

Apesar das convergências entre os dois projetos, as diferenças fundamentais dão origem a duas correntes principais: a escola americana, cujos integrantes descendem de Peirce (Morris, Carnap, Sebeok) e a escola européia, descendente de Saussure (Buyssens, Hjelmslev, 
Prieto, Mounin, Barthes, Greimas, entre outros), muito embora não se possa dizer que cada uma delas constitua um bloco homogêneo (idem ibidem).

Ao longo do tempo, as duas propostas se inter-relacionam, não sendo pertinente falar, nos dias de hoje, numa leitura exclusivamente baseada em Saussure. As vantagens dessas novas abordagens, que chamaremos neste artigo de "lingüístico-semióticas", é que elas permitem, simultaneamente, observar a organização dos sistemas semiológicos ou semióticos e o funcionamento dos signos nos processos de comunicação e interpretação.

No campo da Ciência da Informação, a abordagem lingüístico-semiótica leva a compreender melhor o que é uma linguagem documentária enquanto modo de organização de um conjunto de signos (um sistema estrutural que constitui uma unidade em si mesma e que apresenta semelhanças e diferenças por oposição à linguagem natural e à linguagem artificial), bem como suas características e forma de funcionamento enquanto sistema semiótico particular. Para realizar a discussão, procuraremos, primeiramente, introduzir seus conceitos básicos: signo, interpretante, objeto, semiose e experiência colateral.

\section{OS CONCEITOS BÁSICOS DA SEMIÓTICA}

Na concepção de Peirce, um signo é aquilo que, sob certo aspecto ou modo, representa algo para alguém, está no lugar de alguma outra coisa sob algum aspecto ou capacidade (PEIRCE, 1977). A principal característica do signo é que ele é sempre institucional, estabelecido por convenção, o que o diferencia de um sinal. "A fumaça, por exemplo, é signo do fogo porque uma comunidade assim o instituiu. Do contrário, a fumaça se apresenta exclusivamente como conseqüência do fogo" (TÁLAMO, 1997, p.5).

O signo é sempre uma correlação entre uma forma significante e uma unidade que definimos como significado, sendo semioticamente autônomo em relação aos objetos a que pode ser referido. Dada sua natureza relacional, o signo não existe enquanto entidade física observável e estável: o signo sempre é uma representação parcial do objeto, sendo produto de uma série de relações no interior do sistema em que é formulado - na língua, no sistema da moda, na linguagem gestual etc. A parte observável do signo é o significante, ao qual se associa, por convenção, um significado. (ECO, 1990).

As relações entre o signo e o objeto se expressam através do interpretante, que pode ser visto como "o mecanismo semiótico através do qual o significado é predicado do significante" (ECO, 1990, p.154). É outro signo, ou complexo de signos, que traduz (em) o primeiro signo em circunstâncias adequadas, considerando-se as possibilidades interpretativas 
dadas pelo contexto. Pode, então, ser um sinônimo, um termo equivalente em língua estrangeira, um desenho, uma definição, mas sempre é um desenvolvimento do signo expresso por outro signo, o que permite "eliminar para sempre o espectro ontológico e a falácia realista dos 'referentes' extralingüísticos” (LOPES, 1984, p. 251).

Como elemento do processo de comunicação, o signo é usado para transmitir informação e corresponde à mensagem. Para que funcione desse modo é preciso haver entre emissor e receptor um código comum (ECO, 1990) - por exemplo, a mesma língua, uma mesma fonte básica de significação - o que diferencia os processos de comunicação daqueles de estímulo-resposta. Como elemento do processo de significação, o signo é algo mais difícil de ser compreendido, pois coloca em ação um processo interpretativo. O triângulo semiótico tem sido referido como um elemento através do qual se pode explicar o processo de significação. É preciso lembrar, entretanto, que há várias versões do triângulo cujas diferenças não se restringem às diferentes denominações dadas aos seus vértices. Embora em geral se concorde com a tripartição, sua interpretação varia muito. Na perspectiva da lingüística saussuriana, o signo é uma entidade de duas faces - significante e significado - não tendo importância o referente, já que é extralingüístico.

$\mathrm{Na}$ versão de Peirce, o funcionamento do signo pode ser observado pela imagem abaixo (fig.1):

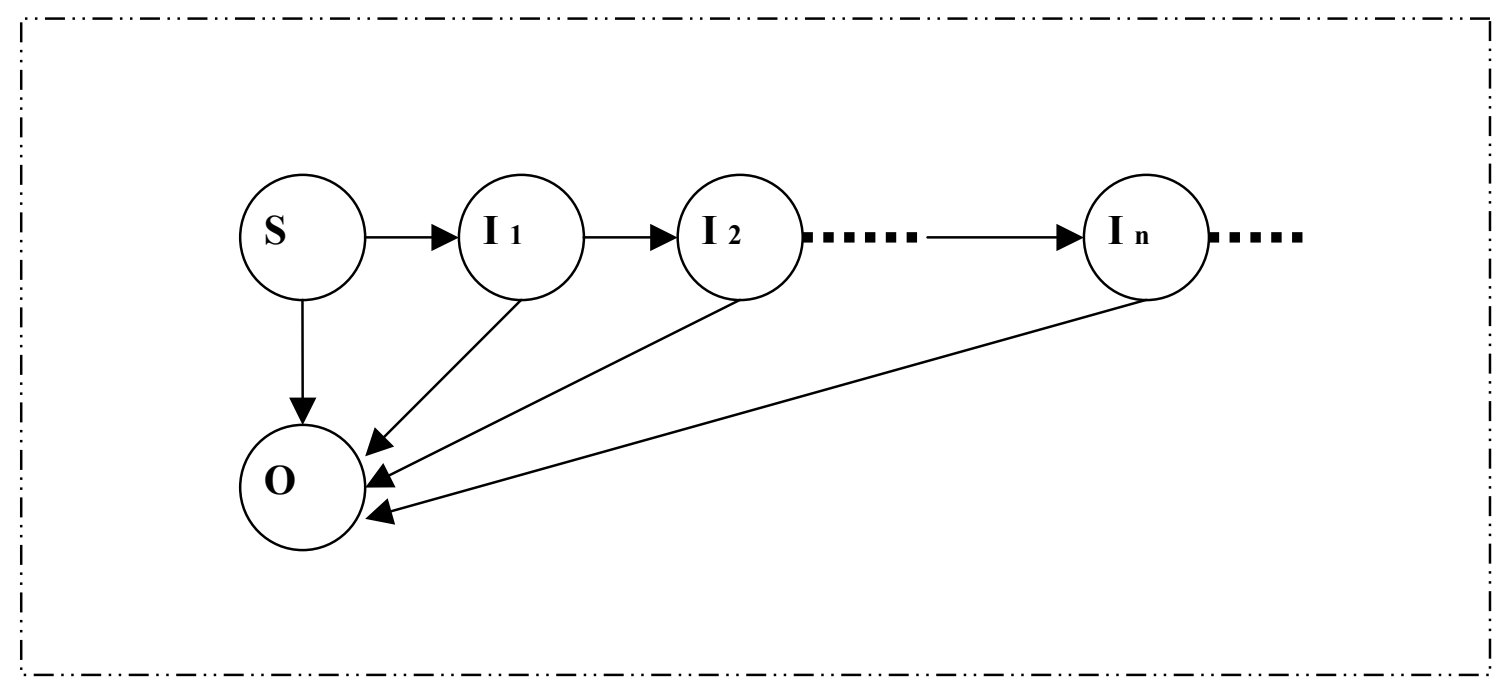

fig. 1

Fonte: GRANGER, G.G. (1974).

Onde:

$\mathrm{S}=$ Signo

$\mathrm{O}=$ Objeto

$\mathrm{I}=$ Interpretante

Enc. Bibli: R. Eletr. Bibliotecon. Ci. Inf., Florianópolis, $2^{\circ}$ número esp., $2^{\circ}$ sem. 2006 
Um signo ou "representamen" é "uma coisa ligada, sob um certo aspecto, a um segundo signo, seu 'objeto', de tal modo que relaciona uma terceira coisa, seu 'interpretante', com este objeto de modo a relacionar uma quarta coisa com o mesmo objeto e assim por diante ad infinitum... “ (PEIRCE, 1955, citado por GRANGER, 1974, p.136). Como ressalta Granger, além do caráter triangular da ligação significante à seqüência de interpretantes, o interessante da proposta peirceana é que o objeto do signo é ele mesmo definido como signo, ou seja, não remete a uma idéia isolada, mas a uma estrutura simbólica da qual ele é elemento.

Entre as coisas e os estados de coisas que envolvem a experiência do mundo - ou os objetos - de um lado, e os signos, de outro, há uma relativa autonomia (RODRIGUES, 1991). Embora a semiótica contemporânea não negue a existência do Objeto, não compartilha da visão do realismo ingênuo que faz corresponder signo e objeto físico, nem da visão mentalista que pretende que ao signo corresponda uma idéia, um conceito ou um estado de consciência (ECO,1990). “A palavra signo será usada para denotar um objeto perceptível, ou apenas imaginável, ou mesmo inimaginável num certo sentido...” (PEIRCE, 1977, p.46). “Um signo não representa nunca um objeto ou referente" (ECO, 1990, p.155), ou nunca o representa completamente. De fato, o ato de referência não torna mais claro o signo, uma vez que é também um signo que interpreta o primeiro signo. O signo só se tornará claro no processo de remissão a interpretantes, no decurso do qual o intérprete decodifica o signo de origem na medida em que ele serve aos objetivos de comunicação desejada ou a usos e aplicações específicas. Segundo a proposta de Eco, cada interpretante de um signo é uma unidade cultural ou semântica. Tais unidades se organizam, numa cultura, na forma de um sistema de oposições, de modo que cada unidade significa relativamente a outras unidades e no contexto onde é observada. Em última análise, esse sistema representa o modo como uma dada cultura segmenta o universo, porém não é possível descrever todo esse universo semântico, seja pelo seu tamanho ou pelo processo de reorganização contínua das unidades culturais (idem ibidem).

À associação de interpretante a interpretante dá-se o nome de semiose, processo pelo qual qualquer coisa age como signo e que compreende três fatores:

- um representamen (primeiro termo de uma relação triádica);

- seu objeto (segundo termo);

- seu interpretante (terceiro termo).

A semiose é, assim, caracterizada como a passagem contínua de signo a signo, que envolve, também, como já afirmamos, um quarto e um quinto fatores: o intérprete e o contexto (DASCAL, 1978).

$\mathrm{Na}$ construção do interpretante pelo intérprete, ou sob outra terminologia, no processo 
de construção do significado, ou processo sígnico, entra em jogo a experiência colateral. $\mathrm{O}$ entendimento desse conceito fica mais fácil através de um exemplo dado pelo próprio Peirce. Se alguém diz que Napoleão era uma criatura letárgica, a interpretação da frase varia conforme o conhecimento anterior da pessoa sobre Napoleão, como sobre o termo letárgico.

\begin{abstract}
"Se ela, antes, nunca ouviu falar de Napoleão, a sentença não significará para ela apenas que uma pessoa ou coisa a que foi atribuído o nome "Napoleão" era uma pessoa letárgica. Pois "Napoleão" não pode determinar a mente da pessoa a menos que a palavra na sentença atraia sua atenção para o homem certo e isto só pode acontecer se, de modo independente, se estabeleceu nessa pessoa um hábito pelo qual essa palavra traz à tona uma variedade de atributos de Napoleão, o homem". Do mesmo modo, "a sentença não pode veicular seu significado a menos que a experiência colateral tenha ensinado a seu Intérprete o que é Letargia, ou o que é que 'letargia'significa nesta sentença"' (PEIRCE, 1977, p.160-161).
\end{abstract}

A experiência colateral é, portanto, um fato independente da ação do signo, algo que se relaciona ao conhecimento anterior de uma pessoa, ou como prefere Peirce, um hábito através do qual um signo traz à tona uma séria de atributos, como um pré-requisito para compreender o significado do signo ou uma prévia familiaridade com aquilo que o signo denota. A experiência colateral não faz parte do Interpretante, mas é um elemento relacionado formador do interpretante. Pode ser compreendido como a experiência prévia, ou o conhecimento de fundo requerido para que o signo seja entendido (ECO, 1984).

A lingüística contemporânea, ao incorporar a abordagem semiótica, corrobora à verificação da realização do signo lingüístico como um evento dinâmico ao qual concorrem, além dos indivíduos ou enunciatários, sua experiência e o contexto de realização.

\title{
3 O SIGNO DOCUMENTÁRIO
}

A informação, no âmbito da Documentação e da Ciência da Informação, é um signo construído intencionalmente para funcionar como elemento de comunicação documentária. A breve exposição de conceitos acima já permite deduzir, todavia, que esse signo não apresenta todas as possibilidades de desenvolvimento semiótico do signo de um modo geral. Se quisermos falar em signo documentário, conseqüentemente, devemos aludir à sua configuração específica no interior de uma classificação geral dos signos, configuração essa que decorre do caráter construído da linguagem documentária - LD.

A LD, construída por analogia à língua e seu funcionamento, pode ser vista como um signo que exerce, simultaneamente, uma função comunicativa e uma função de significação 
nos sistemas documentários onde é utilizada. As linguagens documentárias bem construídas constituem verdadeiras estruturas significantes (BARRETO, 1994) porque articulam, pelo conjunto de suas relações, um sistema uno e autônomo dotado de significado. Para compreender melhor os seus limites e funções, convém compará-la à linguagem natural - LN e à linguagem artificial - LA, sistemas semióticos distintos.

A LN ocupa posição hierárquica predominante entre os sistemas semióticos. É um sistema que compreende signos lingüísticos cujo funcionamento é caracterizado pela semiose ilimitada. Ela é, por excelência, o lugar dos jogos interpretativos que se desenvolvem através de cadeias e associações de interpretantes. As linguagens artificiais, por seu lado, não se caracterizam verdadeiramente como linguagem, pois sendo altamente formalizadas, não dispõem de uma segunda articulação $^{1}$ - responsável pela produtividade e dinamicidade - , como não têm possibilidade interpretativa ancorada na experiência vivida, como na LN, ou seja, relacionada à experiência colateral ou cultural. Nelas, a interpretação é fundada nos símbolos construídos pelas próprias ciências ou técnicas (GRANGER, 1974). Pode-se dizer, portanto, que a LA remete, via sua simbologia, a significados unívocos que, paradoxalmente, dependem, na comunicação, do conhecimento de regras próprias e explícitas. É o que ocorre, por exemplo, com a linguagem da Lógica que tem seu uso condicionado ao conhecimento do significado de sua simbologia e de sua sintaxe própria.

A comparação entre a LN e a LA permite compreender que o caráter intermediário da LD não se deve apenas ao fato dela funcionar como ponte entre sistema documentário e usuário, mas porque conjuga elementos de ambos os tipos de linguagem, constituindo uma terceira de natureza complexa. Por essa condição, os interpretantes da LD correm o risco de remeter, ora à LN, ora à LA.

Observa-se que na LN, uma linguagem dinâmica, os lexemas, ou signos lingüísticos, não têm significação unívoca, dados seu caráter relacional e a possibilidade do desenvolvimento de interpretantes; já na LA, que é estática, os significados são altamente padronizados e unívocos, ou seja, seus interpretantes são determinados e únicos. A rigor, não seria pertinente falar em interpretantes na LA. Na LD, os significados devem ser fixados ou controlados, mas o uso de palavras que, ou são da LN, ou são idênticas às da LN na sua forma, impede que se fale em univocidade estrita; por outro lado, nem sempre os universos

\footnotetext{
${ }^{1}$ A dupla articulação é a propriedade da língua de se dividir em unidades menores - os fonemas, primeira articulação, e os morfemas, segunda articulação. Os fonemas são as menores unidades da língua, sendo desprovidos de significado; os morfemas, combinações de fonemas que constituem as menores unidades de significação da língua, a partir dos quais existe a possibilidade de criação de inúmeras outras unidades significativas. Ex: em 'andar', distinguimos os fonemas a-n-d-a-r; e os morfemas, and-, a partir do qual são produzidos, por exemplo, andaremos, andarás, andarilho etc., e -ar, morfema que serve de terminação verbal a vários outros morfemas, como por exemplo, formar, sonhar etc.
} 
focalizados pelas linguagens documentárias são altamente formalizados. É mais apropriado afirmar que os signos documentários têm seus interpretantes 'controlados', e seu desempenho, para não correr o risco de uma 'camisa de força', devem ser referidos às áreas de conhecimento ou de atividade onde são contextualizados. Sob nosso ponto de vista, as terminologias, como também a teoria terminológica, balizam o processo de construção dos ‘operadores de sentido' da LD (LARA, 1999)².

Os três tipos de linguagem também diferem quanto aos seus objetivos: a LA e a LD desempenham principalmente as funções informativa, ou referencial, e a função prescritiva; a LN não tem função específica e funciona em distintos contextos. Nela, a função referencial ou informativa é a menos importante.

Em resumo, se o signo da LN funciona verdadeiramente com o signo - desencadeando interpretantes e associações de interpretantes num processo aberto, o signo da LA funciona sob pressão de sua simbologia; o signo documentário, por sua vez, funciona a partir do controle de sua significação a partir da referência às terminologias das áreas. É pertinente, pois, identificar os limites da semiose documentária.

\section{A SEMIOSE DOCUMENTÁRIA}

Pelos objetivos pragmáticos da LD de desempenhar a função informativa, não se pode desejar que a semiose dispare aleatoriamente. Ao contrário, a função da comunicação documentária é criar condições para que os signos intencionalmente construídos orientem a interpretação segundo os objetivos do sistema visado. Não se deseja que os signos da LD, ou os termos que conduzem o usuário ao conjunto de textos indexados num sistema de informação, sejam interpretados a partir da experiência individual de cada um. Desse modo, a interpretação ficaria aberta, introduzindo problemas no processo de comunicação documentária.

$\mathrm{Na}$ perspectiva dos sistemas de significação, a LD funciona como uma espécie de 'língua tradutora' que pode ser melhor compreendida se são indicadas as possibilidades interpretativas dos seus termos, seja através da explicitação da rede de associações entre eles que funciona como meio de contextualizá-los de modo relacional -, seja através de definições ou explicações ou, ainda, por meio da reprodução de exemplos onde o termo é utilizado e

\footnotetext{
${ }^{2}$ Para abordar as contribuições da Terminologia à elaboração da linguagem documentária consultar, entre outros: TÁLAMO, M.F.G. (1994). Terminologia e documentação. TradTerm, v.7, n.1, p.141-152. LARA, M.L.G.L.(2004). Linguagem documentária e terminologia. Transinformação, v.16, n.3, p.231-240. Enc. Bibli: R. Eletr. Bibliotecon. Ci. Inf., Florianópolis, $2^{\circ}$ número esp., $2^{\circ}$ sem. 2006 
interpretado na forma desejada pelo sistema. Nesse sentido, ao visar facilitar o acesso e a possibilidade de apropriação da informação, a LD é, nela mesma, um interpretante que sugere hipóteses de interpretação. Pode-se afirmar que a semiose documentária, portanto, funciona sob condições controladas em função dos universos focalizados e dos objetivos visados. De outro modo, ficaríamos no universo aberto de interpretação da LN, que se tem seus benefícios porque não solicita o aprendizado de regras de funcionamento, tem seus problemas em relação à especificidade da recuperação.

A LD funciona como interpretante ou conjunto de interpretantes que são desencadeados por referência a subconjuntos especializados dentro da linguagem geral. Esses subconjuntos, mais do que a LN como um todo, orientam a interpretação das unidades da LD e facilitam a formulação e a compreensão das 'mensagens documentárias'.

Referir o interpretante aos subconjuntos especializados significa propor semelhança de forma e de significado entre um subcódigo lingüístico-semiótico - os signos da linguagem de especialidade - e o código documentário, na sua forma e no seu conteúdo. É a essa operação que denominamos controle e que visa recuperar as propriedades comuns entre as estruturas dos dois códigos: o subcódigo lingüístico-semiótico, de um lado (a linguagem de especialidade, sua terminologia e significados), e o código documentário, de outro. As analogias ocorrem, portanto, no plano da forma e no plano interpretativo, funcionando, de certo modo, como a remessa a uma certa experiência colateral, ou seja, a um conhecimento especializado compartilhado e relativamente estável no domínio ou área de atividade focalizado, e que é organizado por uma rede de relações entre termos.

Propor o 'controle' do interpretante documentário através dessa operação de aproximação entre os dois diferentes códigos não significa, no entanto, propor sua identidade. A própria presença de elementos da LN na LD já impediria que isso ocorresse. Por outro lado, não se pode pretender controlar toda a interpretação, já que ela é individual. A operação visa utilizar a função cognitiva propiciada pela aproximação dos dois tipos de código (e de signos) de modo a sugerir uma possibilidade interpretativa que não é individual, mas organizada por uma comunidade de práticas ao longo da experiência com os conceitos de uma área de especialidade ou de atividade. Além disso, o próprio código documentário, ao propor uma hipótese de organização para construir informação - baseada nos objetivos do sistema, no conhecimento de seus usuários e de suas necessidades - acaba por imprimir, também, sua marca institucional, influindo na forma de leitura que o sistema documentário procura privilegiar (ou a paráfrase informativa que pretende instaurar).

Em resumo, a semiose documentária coloca em jogo operadores semântico-semióticos que possam localizar, no domíno focalizado (por exemplo, no domínio da Política Cultural ou no domínio da culinária) - quais são os termos e como eles se relacionam de modo significativo. A seu modo, a estrutura relacional das linguagens documentárias torna evidente 
essa organização através de sua rede de termos genéricos, específicos, associativos e de equivalência, além dos mecanismos de registro de definições e de notas de explicação. Esses mecanismos, utilizados no momento da busca, auxiliam a interpretação do significado das chaves de recuperação. Portanto, o funcionamento do processo sígnico em contextos documentários, embora funcione por referência a outros códigos semióticos, mobiliza, também, o sistema convenções documentário - que evidencia que a informação é uma construção relativa ao universo-objeto de representação e aos objetivos do sistema de informações.

Confirma-se assim o caráter particular da semiose documentária. A linguagem documentária pode, então, ser considerada, em si mesma, um signo ou um sistema semiótico, como também são signos suas unidades, os descritores. Seus operadores de sentido, ou interpretantes, remetem aos subconjuntos lingüístico-semióticos de especialidade, ou terminologias, que, ao lado das convenções documentárias, são responsáveis pelo funcionamento do processo semiótico de construção da informação em ambientes documentários.

\section{CONSIDERAÇÕES FINAIS}

A reflexão aqui desenvolvida não esgota a análise para a descrição do signo documentário e do processo sígnico correspondente. Numa tentativa de síntese, poderíamos caracterizar o signo documentário como um signo de características próprias cuja organização remete originalmente ao signo lingüístico-semiótico mas que não é potente como ele para a realização como unidade comunicativa e significativa. Eventualmente, o signo documentário pode remeter a símbolos não-lingüísticos (por exemplo, uma fórmula de um elemento químico, numa linguagem formalizada) mas passíveis de tradução lingüística. O signo documentário, enquanto uma unidade de uma linguagem intermediária, tem seu funcionamento dependente de outros sistemas semióticos. O signo documentário faz parte de um sistema sígnico cuja unidade sígnica mínima é o descritor, elemento indivisível. A divisão de um descritor o descaracteriza como signo documentário ${ }^{3}$. Os enunciados construídos a partir do signo documentário são limitados relativamente aos da LN. A semiose documentária, por sua vez, funciona a partir das referências aos universos discursivos dos sistemas semióticos de origem, desde que a LD seja organizada observando-se as referências das áreas de especialidade ou atividade que constituem seu foco. Essa espécie de instrução

\footnotetext{
${ }^{3}$ Os radicais utilizados em buscas não se vinculam aos descritores, mas às palavras, unidades morfológicas. Os descritores podem coincidir com a palavra, porém são mais freqüentemente sintagmas nominais ou, na terminologia da Terminologia, termos.

Enc. Bibli: R. Eletr. Bibliotecon. Ci. Inf., Florianópolis, $2^{\circ}$ número esp., $2^{\circ}$ sem. 2006
} 
interpretativa pode ser descrita na forma do arranjo relacional dos termos no interior da LD, como também na forma de metadados ou definições (LARA, 1999).

Da discussão que nos propusemos a realizar, pode-se concluir que a atividade documentária constitui uma modalidade de produção de documentos, não de sua reprodução. O documento é uma unidade textual organizada sob uma forma e um conteúdo e, como tal, constitui uma unidade de interpretação. Colocado nos sistemas de informação, o documento ou o texto documentário - é sujeito, novamente, à interpretação. Por esse motivo, mais do que mostrar a natureza semiótica da linguagem documentária e delimitar o signo documentário, a abordagem semiótica tem a vantagem de colocar em relevo o intrincado processo de construção da significação e de sua interpretação.

\section{REFERÊNCIAS}

BARRETO, A.A. A questão da informação. São Paulo em Perspectiva, v.8, n.4, p.3-8, out./dez., 1994.

CINTRA, A.M.M.; KOBASHI, N.Y.; LARA, M.L.G. de; TÁlAMO, M.F.M.G. Para entender as linguagens documentárias. 2.ed. São Paulo : Polis, 2002.

DASCAL, M). Les semiologies contemporaines. In: DASCAL, M. La semiologie de Leibniz. Paris : Aubier Montaigne, 1978. Cap. 2.

ECO, U. Conceito de texto. Trad. de Carla de Queiroz. São Paulo : T.A. Queiroz; Ed. Universidade de São Paulo, 1984.

ECO, U. O signo. Trad. De Maria de Fátima Marinho. 4.ed. Lisboa : Presença, 1990.

GRANGER, G.G. Filosofia do estilo. São Paulo : Perspectiva, 1974.

LARA, M.L.G. Linguagem documentária e terminologia. Transinformação, v.16, n.3, p.231240, 2004.

LARA, M.L.G. Representação e linguagens documentárias: bases teórico-metodológicas. 280p. Tese (Doutorado em Ciências da Comunicação). São Paulo : Escola de Comunicações e Artes, Universidade de São Paulo, 1999.

LOPES, E. Fundamentos da lingüística contemporânea. São Paulo : Cultrix, 1984.

PEIRCE, C.S. Semiótica. Trad. de José Teixeira Coelho Netto. São Paulo : Perspectiva, 1977. RODRIGUES, A.D. Introdução à semiótica. Lisboa : Presença, 1991.

TÁLAMO, M.F.G.M. Linguagem documentária. São Paulo : Associação Paulista de Bibliotecários, 1997. (Ensaios APB, n.45)

TÁLAMO, M.F.G. Terminologia e documentação. TradTerm, v.7, n.1, p.141-152, 1994.

\section{Abstract}

We discuss the contribution of the linguistic-semiotic approach to the understanding of documentary language as well as the possibilities of the documentary sign and semiosis. We present a synthesis of the main semiotic concepts - sign, object, interpretant, collateral experience ad semiosis - and try to characterize the documentary sign and semiosis focusing the two related semiotic systems: the natural language and the artificial language. The 
documentary sign is characterized as a particular sign, wich semiosis depends on the interpretants in special languages focused.

Keywords: Semiotics. Documentary language. Documentary sign. Documentary semiosis. Documentary interpretation.

Originais recebidos em: 15/06/2006. 